\title{
Menoridade e Periculosidade: intersecções e assujeitamentos
}

\author{
Minority and Dangerousness: intersections and subjections
}

\author{
Alessandra Teixeira ${ }^{a}$ e Fernanda Emy Matsuda ${ }^{b}$
}

\begin{abstract}
Resumo Este artigo pretende discutir como, na experiência nacional, a partir dos discursos médico-legal e criminológico e das práticas de controle e punição dirigidas à infância e à juventude pobre e abandonada, as categorias menoridade e periculosidade se articularam, apropriando-se do instituto da periculosidade presumida (aplicada a adultos vadios e reincidentes no Código Penal de 1940), para diferenciar a menoridade, necessariamente pobre, da infância e juventude abastadas, eventualmente infratora. $\mathrm{O}$ artigo recorre a análise da normativa (entre as décadas de 1920 e 1950), levantamento e análise de material bibliográfico, bem como a dados e discursos de Relatórios Policiais das décadas 1930 e 1940, no estado de São Paulo, como fontes primárias.
\end{abstract}

Palavras-chave menoridade; periculosidade; controle; punição; delinquência; sujeição

Abstract This article aims to discuss how the categories of minority and dangerousness were articulated, in the national experience, from criminological and medico-legal discourses and practices of control and punishment towards child and youth poverty, through the appropriation of the institute of presumed dangerousness, applied to vagrant adults and recidivists as established by 1940's Criminal Code, to differentiate minority, necessarily linked to poverty, from wealthy child and youth, eventually lawbreaker. The article makes use of the analysis of regulations (between 1920 and 1950 decades), survey and analysis of bibliographic material, as well as deals with data and speeches extracted from the Police Reports referring to the 1930 s and 1940s, in the state of São Paulo, as primary sources.

Keywords minority; dangerousness; control; punishment; delinquency; subjection

a Doutora e Mestre pelo Programa de Pós-Graduação em Sociologia da USP. Pós-doutora em Ciências sociais pela UNESP/Marília. Bacharel em Direito. Professora adjunta da Universidade Federal do ABC - UFABC.

b Doutora e Mestre pelo Programa de Pós-Graduação em Sociologia da USP. Bacharel em Direito e em Ciências Sociais. 


\section{INTRODUÇÃO}

Este artigo pretende discutir como as categorias menoridade e periculosidade se articularam, na experiência nacional, a partir dos discursos médico-legal e criminológico e das práticas de controle e punição dirigidas à infância e à juventude pobre e abandonada. Situa-se a emergência dessa articulação a partir da entrada em vigência do Código Penal de 1940 e, sobretudo, do Decreto 6.026 de 1943, que vai se apropriar do instituto da periculosidade presumida, aplicada a adultos vadios e reincidentes, para diferenciar a menoridade, necessariamente pobre, da infância e juventude abastadas, eventualmente infratora.

Sustentamos que essa reapropriação do conceito de "periculosidade social" consistiu no momento decisivo para o ingresso da menoridade num projeto de controle policial e institucional potencialmente mais violento e assujeitador, ${ }^{1}$ estreitando as fronteiras que antes separavam mais nitidamente a menoridade abandonada da delinquência tornando a primeira alvo preferencial da gestão dos ilegalismos.

Além da análise normativa do período e do extenso material bibliográfico, foram utilizados, como fontes primárias, dados e discursos extraídos dos Relatórios Policiais referentes às décadas de 1930 e 1940, no estado de São Paulo.

\section{O MENOR E SUA LONGA HISTÓRIA DE SUJEIÇÕES}

Para compreender como a criança e o adolescente passam a ocupar um lugar de destaque nas políticas de controle e repressão e nos discursos normalizadores, ou seja, na história da gestão dos ilegalismos em São Paulo, um caminho profícuo é indagar quando e de que forma esses atores, ou melhor, a "infância abandonada" se constituiu como um problema. Esse foi o ponto de partida adotado por Alvarez (1989) para elucidar a historicidade do menor enquanto categoria jurídica e institucional, quando do advento do Código de Menores, em 1927.

Uma primeira indagação deve se referir à construção do conceito de menoridade, ou seja, o processo pelo qual infância e adolescência converteram-se em

1 A referência maior para os conceitos de sujeição e assujeitamento está na obra de Michel Foucault, mobilizada por ele para descrever os processos de constituição do sujeito ocidental assujeitado nas redes contínuas de obediência, e que é subjetivado pela extração de verdade que a ele se impõe (FoucAult, 2004, p.188). Alvarez (1989), ao falar do menor enquanto categoria jurídica e institucional no Código de Menores de 1927, tutelado por "um dispositivo legal de poder", "sem responsabilidades, mas também sem diretos", identifica ali sua condição de assujeitado. Adorno (1993) também recorre à noção para descrever o processo de criminalização que converte as crianças em menores, pelo qual "abandonam a condição de sujeito para se tornarem objeto da história dos outros, dos homens 'de bem', da 'sociedade educada', das instituições de controle” (ADORNO, 1993, p.183-184). 
menoridade. Corrêa (1982) localiza a construção da categoria menor no Brasil a partir da confluência entre medicina legal e direito, no final do século XIX, para designar a infância pobre, destituída de laços familiares ou vínculos socialmente reconhecíveis. "Transformado de adjetivo em substantivo" (CoRrÊA, 1982, p. 62), o menor abandonado emerge, nas primeiras décadas do século XX, como categoria socialmente produzida, resultado da incorporação contundente dos postulados "sociobiológicos" do pensamento de Nina Rodrigues e seus discípulos na experiência social brasileira.

É nesse momento, como descreve Alvarez (2004), que no Brasil os criminologistas da nova escola penal irão se ocupar de modo mais acurado das categorias sociais a exigir "tratamento jurídico diferenciado", ${ }^{2}$ entre elas o menor, que se tornará o mais destacado objeto de uma retórica que converterá o combate à infância abandonada no verdadeiro projeto civilizador da nação.

Desse empreendimento resultará o Código de Menores de 1927, um dispositivo disciplinar e de controle, nos termos de Alvarez (1989), voltado a

um segmento da população que antes parecia ainda indiferenciado, disperso entre as figuras dos expostos, enjeitados, infantes trabalhadores, crianças pobres em geral, que, a partir do Código de 1927, passarão a girar em torno de uma categoria discursiva e institucional única - o menor. Este, assujeitado por um novo projeto de institucionalização, definido pela lei, e que articulava de modo elaborado a ação de instituições estatais e de instituições privadas, passa a ser sujeito de uma nova trajetória jurídica e institucional, que hoje já conhecemos bastante. Este sujeito, partindo das classes pobres, terá no seu horizonte o trabalho ou a delinqüência. Para garantir essa trajetória, a lei concebe os parâmetros gerais, e as instituições garantem a reprodução concreta do processo de sujeição (AlvareZ, 1989, P.148).

Embora convertido numa categoria institucionalizável, é certo que o menor, enquanto um dos alvos preferenciais do aparato repressivo, manteve-se também objeto das práticas policiais de controle soberbamente representadas pelas detenções correcionais. ${ }^{3}$ Por esse instrumento policial, a gestão diferencial da lei em

2 As demais categorias seriam os loucos e as mulheres, como recupera Alvarez (2004) a partir da proposição de Tobias Barreto.

3 Consistiram em práticas policiais autointituladas correcionais, que vigoraram do Império à década de 80 do século XX. Tais prisões não se voltavam a condutas criminais propriamente ditas, ou mesmo para o cometimento de contravenções, mas eram dirigias a determinados tipos sociais e eram operacionalizadas à margem dos termos legais e à revelia de uma acusação formal, 
terras pátrias enfatizou o controle das classes populares através de práticas ilegais de detenção temporária e cotidiana, em detrimento do ciclo completo da punição e do encerramento institucional de caráter disciplinar (TeIXEIRA, 2012).

Desse modo, embora na base da criação do Instituto Disciplinar, em 1901, ${ }^{4}$ já estivessem os anseios de segregar a infância abandonada e vadia do espaço da cidade, para então "recuperá-la", sua função jamais foi efetivamente atendida. Do mesmo modo que a Colônia Correcional da Ilha dos Porcos, a espécime institucional para adultos vadios, apenas uma parcela ínfima de menores era remetida ao Instituto Disciplinar. Fausto (2000) constatou, ao menos até 1924, que o Instituto abrigou "apenas algumas dezenas de meninos" (p.97), prevalecendo, de outro lado, o alto percentual de menores detidos "sem processo", em sua maioria por contravenções e pequenos delitos patrimoniais.

A entrada em vigência do Código de 1927 não alteraria essa realidade, tendo havido, na verdade, uma intensificação das “apreensões” de menores a partir dos anos 30. Em muito o maior controle dirigido aos menores a partir da década 30 se insere no mesmo contexto que levou ao acirramento da perseguição à vadiagem no período, quando, em 1935, o aparelho policial foi em parte reestruturado para ampliar as atividades de controle às classes populares, estendendo-se à Delegacia de Vigilância a competência para prender mendigos e menores, pelo que ela passaria a se designar Delegacia de Vigilância e Capturas.

O relatório do Chefe de Polícia de 1936 chama a atenção para um dado que merece, de fato, destaque: o número de menores apreendidos no Estado saltou de apenas 70 no ano de 1926 para $2.155^{5}$ em 1935, sendo a imensa maioria deles, 1.886, apreendidos na capital. O chefe de polícia atribui essa alta a dois fatores. O primeiro seria, justamente, o já citado reaparelhamento das forças policiais através do Decreto 7.223 de 21 de junho de 1935, pelo qual se criou uma Seção de Menores e Desaparecidos junto à Delegacia de Vigilância e Capturas. O segundo fator seria a participação crescente de menores nos crimes patrimoniais na cidade. Nesse ponto, embora o relatório não apresente dados que comprovem a afirmativa,

sem a formação do devido processo. A mais persistente modalidade consistiu na "prisão para averiguação" (TEIXEIRA, 2012).

4 O Instituto Disciplinar foi criado em 1902 para reclusão dos menores abandonados e aqueles condenados por vadiagem, sendo que dos 9 a 14 anos receberia apenas os abandonados, pequenos vadios e viciosos, e entre os 14 e 21 anos aqueles condenados por vadiagem.

5 Esse número se refere à apreensão de menores abandonados e tachados como vadios. Embora o relatório não esclareça de modo expresso, estão provavelmente excluídos desse contingente os infratores (os acusados de cometerem crimes). E certo que entre os infratores e não infratores há uma tênue linha que os separa, já que os dispositivos de controle a essa população são norteados pela noção de ilegalismo e sua gestão, e não pelas categorias jurídicas e criminais. 
fica claro como a percepção social, aqui traduzida por um documento oficial, já se delineia no sentido de atribuir ao menor as causas não apenas de desordens sociais, mas de delitos que atentassem contra a propriedade.

Num trecho elucidativo do Relatório de 1936, o Delegado de Investigações de Furto está a exigir uma vigilância ainda mais estreita sobre os menores, atribuindo a eles e aos empregados domésticos a responsabilidade pelo suposto aumento de furtos cometidos na cidade:

Julgo de meu dever, suggerir a conveniência de um entendimento entre a alta direcção da policia e os poderes e repartições competentes, com referencia à necessidade, cada vez maior, de uma vigilancia constante sobre os menores abandonados e pervertidos e sobre os empregados domésticos, porque uns e outros têm contribuído extraordinariamente para a elevação suprehendente do nosso coefficiente de criminalidade, com relação aos delictos contra a propriedade (Relgab, 1936, p.15).

Percebido como um problema social, o menor, na sua condição de abandonado, a quem se impingiam atributos morais, legais ou não, de "vicioso", "transviado" ou pervertido", é visto nesse momento como um potencial protagonista da criminalidade patrimonial. Seu controle, no entanto, como das populações-alvo em geral, permanece circunscrito às apreensões cotidianas e ilegais, mas essa detenção transitória angustiava as autoridades que se ressentiam da ausência de um projeto disciplinador de maior permanência, ou seja, de instituições totais, que, em cumprimento ao Código de 1927, dessem conta do menor enquanto "problema social", através de seu internamento vindouro, como se depreende do trecho abaixo:

Quanto aos menores, os institutos destinados á sua reeducação, de tão transcendente função social, não se acham devidamente aparelhados, segundo se deprehende das constantes reincidencias dos mesmos na criminalidade e no abandono, depois de serem remettidos ao Juizo competente,o qual acaba de dirigir á Delegacia de Vigilancia e Capturas um officio, que nos deixa em situação extremamente embaraçosa, de vez que, não podendo, por expressa disposição de lei e de accordo com ordens superiores, conservar detidos, á nossa ordem, os menores aprehendidos, tambem não podemos encaminhal-os ao MMo. Dr. Juiz de Menores [...] (RCPPOLSP, 1939, p.15). 
O relatório se referia a um oficio encaminhado pelo Juízo de Menores à Delegacia de Vigilância e Capturas, em 1937, proibindo o envio maciço de menores àquele órgão, já que, diante da ausência de vagas nas parcas instituições existentes para esse fim, eram sistematicamente devolvidos às ruas. Para se ter uma ideia, no ano de 1936, o chefe de polícia informou que, dos 1.203 menores apreendidos na capital, 583, quase metade deles, correspondiam efetivamente a abandonados e, por isso, foram enviados ao Juízo de Menores, sendo 469 entregues às famílias, 90 a outras delegacias e o restante encaminhado ao interior de São Paulo ou a outros estados (RELGAB, 1936).

O chefe de polícia se ressente, assim, de que as duas instituições públicas existentes para "acolher" menores abandonados, o Abrigo de Menores e o Reformatório Modelo, ${ }^{6}$ já se encontravam, àquela época, superlotados, pese, segundo ele, a recém-criada Assistência Social do Estado, em 1934, ter destinado auxílio financeiro e amparo à infância abandonada. E, embora não apresentando dados que atestem sua afirmativa, estabelece uma associação entre ausência de institucionalização e participação crescente de menores nos crimes de roubo na cidade:

O Abrigo e o Reformatório já se acham superlotados, enquanto que os menores transviados continuam a agir na cidade, contra a propriedade, numa porcentagem de mais de 10 por cem, como acaba de accentuar a autoridade de Roubos (RELGAB, 1936, p.15).

O que está presente na ordem discursiva em relação ao menor é a ideia de que sua condição de abandono, pobreza, ausência de laços institucionais permanentes já traz em si a potencialidade do crime, algo que, embora não se inaugure nesse momento, se perfaz com mais nitidez a partir de então. Mais intensamente do que ocorria com a vadiagem, a menoridade, enquanto categoria forjada pelo discurso médico e jurídico, será o resultado mais acabado da articulação entre abandono e delinquência, como observou Alvarez (1989). Isso possibilitou que, em torno do menor, se estabelecessem estratégias mais acintosas de gestão diferencial da lei por parte do Estado, passando pelas detenções ilegais, extorsões mais sistemáticas, até a violência institucional, no contexto da cidade, ao longo do século XX.

6 No relatório faz-se menção a entidades privadas, que, inclusive, receberiam recursos do Estado, embora não sejam apresentados quer seu número, quer a quantidade de menores que abrigaria. Destacava-se, já a essa época, a importância das entidades religiosas, em especial a Liga das Senhoras Católicas, junto a esse mercado. Até a década de 50, as entidades religiosas, com destacamento para as católicas, representavam 50\% das instituições existentes para abrigamento de menores, segundo relatório do CEBRAP (1972). 


\section{O ESTATUTO CIENTÍFICO DA PERICULOSIDADE}

A noção de periculosidade, embora apareça com frequência nos discursos que versam sobre o crime e o castigo, não é um conceito jurídico. Trata-se de uma ideia que nasceu da criminologia, quando esta tomou para si uma noção advinda do alienismo e passou a utilizá-la para definir políticas criminais.

O início da relação entre justiça criminal e medicina pode ser localizado na primeira metade do século XIX, quando noções pertencentes ao campo da psiquiatria passaram a guardar relação com a questão criminal, como a noção de "monomania homicida" elaborada por Esquirol (1772-1840) em 1808. A ideia de periculosidade, no entanto, é um desdobramento do termo temibilità, cunhado por Garofalo (1851-1934) em 1880, que entendia ser ela a "perversidade constante e ativa do delinquente e a quantidade do mal previsto que se deve temer por parte do mesmo delinquente" (GAROFAlo apud Bruno, 2000, p.774). Assim, é do cruzamento entre medicina e direito que surge a concepção de periculosidade (QueIrolo, 1984).

A teoria clássica do direito penal, pautada na ideia de livre arbítrio e de imputação de responsabilidade, viu-se desafiada pela questão dos "crimes sem razão", como aponta Foucault (2006). O pressuposto da teoria clássica era a capacidade de autodeterminação do sujeito, ou seja, sua faculdade de escolher entre cometer ou não um crime, de acordo com um critério de racionalidade. No momento em que a racionalidade do crime foi colocada em xeque por esse sistema jurídico alicerçado no livre arbítrio e na responsabilização do sujeito pelo ato contrário à lei por ele cometido, a psiquiatria passou a intervir no sistema de justiça criminal (MATSUDA, 2009).

No centro da discussão a respeito dos crimes sem razão, que clamavam as considerações médicas nos tribunais, a categoria da monomania é significativa. É no âmbito do alienismo francês que aparece a noção de monomania, cujo surgimento esteve ligado a uma definição da loucura por meio do delírio, e que aos poucos substituiu essa concepção. Pinel (1745-1826), ao promover a "libertação" dos loucos dos grilhões nos asilos e ao observar sistematicamente os sintomas da loucura, foi o primeiro a aceitar a existência de uma loucura sem delírio, uma loucura parcial, que poderia atingir apenas uma parcela do estado mental do indivíduo: o entendimento poderia ser perfeito, enquanto o controle dos impulsos, não (Foucault, 2003). Seu discípulo Esquirol é quem desenvolve essa percepção de uma loucura desprovida da sintomatologia do delírio e propõe o conceito de monomania homicida, uma subclassificação da monomania instintiva, que imediatamente inflamou os debates entre a psiquiatria e o direito penal. 
As monomanias poderiam atingir tanto o nível dos instintos - monomanias instintivas - quanto o nível do afeto ou do sentimento - monomanias raciocinantes. Na segunda hipótese, enquadravam-se pessoas que, apesar de lúcidas e inteligentes, apresentavam "distúrbios do caráter ou do senso moral" (CARRARA, 1998, p.74).

Foi por intermédio da noção de monomania que se forjou a concepção da loucura enquanto alienação mental, como doença não necessariamente caracterizada pelo delírio. Foi a concepção de monomania, principalmente da instintiva, que permitiu visualizar com clareza em que se transformou a loucura no correr do século XIX: um mal que implicou a objetificação do homem e que passou a estendê-lo ao nível das coisas (FoucAult, 2003). A ameaça à ordem social representada pelo louco se agrava com o caráter de imprevisibilidade, seus sinais sendo imperceptíveis para o olho não especializado.

A noção da doença mental como um estado permanente, impassível de cura, consolida-se, na segunda metade do século XIX, no conceito de degeneração, que acaba se sobrepondo à monomania. Morel (1809-1873), discípulo de Esquirol, apropriou-se de um termo corrente entre naturalistas e etnólogos para designar variações étnicas e raciais - o que significava dizer os povos "não brancos" - e passou a empregá-lo com conotação patológica.

O diagnóstico de degeneração mental proposto por Morel não substituía o de doença mental. As doenças não degenerativas seriam passíveis de cura e, quando não fossem tratadas, poderiam ser transmitidas aos descendentes, sendo a causa da degeneração em outra geração, portanto. Contudo, a degeneração comportava uma origem híbrida, podendo ser natural ou sociomoral. As principais fontes de degeneração seriam a malária, o álcool, o ópio, a constituição geológica do solo, as fomes, as epidemias, as intoxicações alimentares, as indústrias, as profissões insalubres, as doenças infecciosas ou congênitas, a miséria, o temperamento doentio, a imoralidade dos costumes e as influências hereditárias (GENIL-PERRIN apud CARRARA, 1998, p.86).

A incurabilidade da degeneração colocava em último plano o enfoque terapêutico, o que reduzia o papel dos psiquiatras à prevenção, a partir da identificação dos estigmas e o afastamento das fontes. Isso contribuiu para alçar a ciência psiquiátrica ao estatuto de medicina social.

Tanto a figura da monomania quanto a da degeneração evidenciam a preocupação médica com a interpretação do fenômeno criminal. Entretanto, ver no crime a manifestação da doença significava desqualificá-lo, já que ele seria um sintoma de uma moléstia. Como afirmado anteriormente, até o final do século XIX, em sendo detectada a doença, saía de cena o sistema de justiça criminal. Apenas com 
a antropologia criminal é que o aparelho judiciário tem seus alicerces abalados, já que se apresentava uma nova concepção do crime e do criminoso.

A antropologia criminal, que se arrogava o estatuto de ciência positiva, baseava-se nas técnicas da antropometria e da craniometria, mais tarde chamada frenologia, desenvolvidas por Gall (1758-1828) e Broca (1824-1880). Esses procedimentos se voltavam à medição anatômica dos indivíduos, com especial atenção ao cérebro, e geravam estatísticas que apontavam a existência de padrões e desvios. Para Broca, as raças humanas podiam ser hierarquizadas em uma escala linear de valor intelectual: indivíduos brancos do sexo masculino teriam naturalmente uma posição mais elevada, enquanto mulheres, negros e pobres estariam em degraus inferiores.

Lombroso (1835-1909) deu um passo adiante na elaboração teórica de seus colegas médicos que postulavam a superioridade de certas raças humanas ao associar tendências antissociais e perigosas apresentadas por indivíduos brancos à presença de traços fisionômicos análogos aos das raças inferiores. Além disso, sua análise o conduziu à construção do criminoso nato, o Homo criminalis. A diferença em relação ao degenerado residia no atavismo, na condição do criminoso nato como um ser evolutivamente regressivo.

Ao lado dos juristas Ferri (1856-1929) e Garofalo, o médico psiquiatra Lombroso fundou a Escola Positiva, que produziu efeitos duradouros ao difundir a concepção biodeterminista da ação humana. Para esse movimento, nem todos aqueles que cometiam crimes o fariam em razão de uma disposição atávica; havia, ao contrário, múltiplas classificações de criminosos.7 Contudo, é a partir dessa noção de um indivíduo irrecuperável, incorrigível e reincidente que se arma a oposição à Escola Clássica, incapaz de dar conta da função de defesa da sociedade contra os ataques dessa figura especialmente perigosa. Embora esses criminosos não pudessem ser responsabilizados, já que desprovidos de livre arbítrio, não poderiam, no entanto, ficar isentos de uma medida que assegurasse a proteção da sociedade. Garofalo anunciava em sua obra Criminologia que o crime deveria ser avaliado pelo critério da temibilidade do delinquente e a pena variaria de acordo com o perigo por ele representado, desde sua exclusão por prazo indeterminado até sua execução (MirANDA, 2009).

Apesar das dificuldades enfrentadas para a aceitação de suas propostas de reforma do sistema penal, a Escola Positiva deixou seu legado e alguns de seus

7 Segundo a classificação de Ferri (apud CARRARA, 1998, p.109), haveria criminosos loucos (loucos morais, loucos raciocinantes, idiotas, maníacos persecutórios, epiléticos degenerados), criminosos de ocasião, criminosos por paixão e criminosos por hábito (reincidentes). 
postulados são ainda hoje sentidos nas legislações relativas ao crime. A maior contribuição desse pensamento foi a noção de periculosidade, à qual está atrelada a negação de direitos aos transgressores das normas sociais, não apenas pela ameaça que representam, mas também pela ausência de perspectivas quanto à sua recuperação. A constatação de que determinados indivíduos são incapazes de conviver na sociedade, já tendo dado mostras dessa incapacidade com o cometimento de um crime, faz recair sobre eles toda sorte de intervenções pelo aparato estatal, inclusive sua eliminação (MATSUDA, 2009).

\section{APREENSÕES CORRECIONAIS E A META INSTITUCIONAL: A INCORPORAÇÃO DA NOÇÃO DE PERICULOSIDADE}

Durante o Estado Novo, estratégias de controle social amplamente representadas nas detenções correcionais não apenas ganharam força, como foram respaldadas e legitimadas no centro mesmo do aparato do Estado, alicerçadas pelo discurso moralizador como um braço do regime autoritário. Para se ter uma ideia da expressividade que essas práticas vão ganhar nos aparatos de controle, entre 1937 e 1943 a taxa de detidos correcionalmente no estado de São Paulo, superou a cifra de 1000 detidos por 100 mil habitantes (TeIXeIRA, 2012).

Nesse contexto, a detenção correcional de menores também passa a sofrer um grande impulso, alavancada pelo discurso e práticas moralizadoras do período. No ano de 1941, tem-se notícia de uma "Campanha de Saneamento Social” no interior do estado, que teria visado justamente promover seus fins "por meio da apreensão dos meninos abandonados ou em via de perder-se" (A Estatística Policial-Criminal Do Estado De São Paulo, 1942, p.85).

Assim, em nome de uma verdadeira cruzada em prol da infância moralmente saudável, o Estado prendeu correcionalmente, em média, 1.700 menores por ano, entre 1938-1943, e através do mesmo instrumento e das mesmas motivações ilegais utilizadas para os adultos.

À parte, contudo, os prevalecentes mecanismos de controle que seguiam seu ritmo frequente, no plano da institucionalização, alguns dispositivos legais introduzidos durante a ditadura Vargas alterariam de modo importante o tratamento jurídico imposto ao menor.

Com a legislação penal de 1940 - o Código Penal e a Lei de Contravenções Penais - pese a inclinação de Vargas ao positivismo, foi paradoxalmente mantida a tradição liberal dos códigos criminais no país, havendo, contudo, a previsão de um elemento que destoava dessa matriz: o conceito de periculosidade. A referida legislação condicionou a ideia de culpa e de proporcionalidade da pena à noção de 
imputabilidade, cujo significado foi cuidadosamente tecido de modo a construir seu avesso na noção de periculosidade.

O Código Penal de 1940 consagrou o modelo duplo-binário pelo qual a determinadas categorias de indivíduos poderia ser aplicada pena e medida de segurança sucessivamente, como se nesses sujeitos se perfizesse uma figuração híbrida, algo como imputáveis, porém perigosos. Já aos loucos criminosos estava excluída a imputabilidade, só se aplicando a medida de segurança. A medida de segurança não é definida como uma pena, mas como modalidade de tratamento, não apresentando prazo de duração, nem termo máximo, já que, a princípio, sua vinculação não é ao crime, e sim a um estado de periculosidade apresentado pelo autor do fato. ${ }^{8}$

O CP de 1940 dispunha ser a periculosidade presumida nos casos de reincidência, quando o agente estivesse "em estado de embriaguez pelo álcool ou substâncias de efeitos análogos, quando habitual a embriaguez", e quando se trata de inimputáveis (ou loucos-criminosos) (BRAsIL, Decreto-lei 2.848, 1940, art.78). A Lei de Contravenções Penais elencava as possibilidades em que a periculosidade deveria ser presumida: aos condenados por vadiagem, mendicância e os reincidentes em jogo de azar e jogo do bicho (Brasil, Decreto-lei 3.668, 1941, art.14).

Desse modo, a periculosidade e, mais precisamente, sua presunção, foi a peça de articulação de um projeto disciplinador cujo fim era a segregação de categorias socialmente perigosas, excluindo-as das garantias previstas nas disposições liberais do Código Penal. Assim, aos socialmente perigosos ${ }^{9}$ (vadios, mendigos, ébrios, prostitutas, reincidentes), uma vez atribuído o estatuto da periculosidade, era aplicada a "universalidade" da pena (o castigo legal, com seu termo), acrescida, contudo, da "profilaxia" da medida de segurança (o campo profícuo da disciplina, com sua indeterminação).

E será em torno dos menores que se verificará a confluência perfeita desse duplo dispositivo, lei e norma, estendendo os mecanismos de sujeição a limites potencialmente muito mais largos. Embora nem o Código Penal nem a Lei de Contravenções Penais pudessem ser aplicados aos menores, havendo previsão expressa no primeiro sobre a necessidade de se remeter a uma legislação especial

8 A reforma da parte geral do Código Penal em 1984 alteraria esse modelo, consagrando um regime chamado vicariante, pelo qual apenas aos inimputáveis é possível a aplicação de medida de segurança, eliminando, ao menos parcialmente, a imputação da categoria periculosidade para os penalmente imputáveis. Sobre a prevalência da noção de periculosidade em outros institutos jurídicos penais conferir Fry e Carrara (1986) e Matsuda (2009).

9 Com essa formulação, chegava-se muito próximo do conceito de "periculosidade social" defendido por Virgílio de Sá Pereira também em seu projeto de código penal, apresentado em 1927 (Matsuda, 2009). 
em caso de menoridade delitiva, um decreto visando regulamentar as prescrições do Código Penal dispôs sobre a aplicação da periculosidade presumida aos menores abandonados, pese tal decreto não consistir em uma legislação especial e, por estar abaixo dela na hierarquia legal, não ter o poder de revogá-la.

Assim, o Decreto-lei 6.026 de 24 de novembro de 1943 constituiria o momento decisivo para que a periculosidade passasse a designar ostensivamente a infância pobre e abandonada e a operar como princípio norteador de sua institucionalização.

Art. $2^{\circ}$ São as seguintes as medidas aplicáveis aos menores de 14 a 18 anos:

a) se os motivos e as circunstâncias do fato e as condições do menor não evidenciam periculosidade, o Juiz poderá deixá-lo com o pai ou responsável, confiá-lo a tutor ou a quem assuma a sua guarda, ou mandar interná-lo em estabelecimento de reeducação ou profissional e, a qualquer tempo, revogar ou modificar a decisão;

b) se os elementos referidos na alínea anterior evidenciam periculosidade o menor será internado em estabelecimento adequado, até que, mediante parecer do respectivo diretor ou do órgão administrativo competente e do Ministério Público, o Juiz declare a cessação da periculosidade.

$\S 1^{\circ}$ Em casos excepcionais, o Juiz poderá mandar internar o menor perigoso em secção especial de estabelecimento destinado a adultos, até que seja declarada a cessação da periculosidade, na forma da alínea b deste artigo.

$\S 2^{\circ}$ Completada a maioridade sem que haja sido declarada a cessação da periculosidade, observar-se-ão os parágrafos $2^{\circ}$ e $3^{\circ}$ do art. $7^{\circ}$ do Decreto-lei n ${ }^{\circ} 3.914$, de 9 de dezembro de 1941.

$\S 3^{\circ}$ O Juiz poderá sujeitar o menor desligado em virtude de cessação da periculosidade a vigilância, nas condições e pelo prazo que fixar, e cassar o desligamento no caso de inobservância das condições ou de nova revelação de periculosidade (BRASIL, Decreto-lei 6.026, 1943, grifos colocados).

Foi através desse decreto que se consagrou, no plano jurídico, a divisão entre a infância e a juventude de um lado, e a menoridade, atribuída como perigosa, de outro. De acordo com suas disposições, a um jovem entre 14 e 18 anos que cometesse um crime, mas não apresentasse periculosidade, destinava-se um tratamento educativo (manutenção com os pais ou eventual envio à entidade profissionalizante 
ou reeducativa). Já a um menor infrator perigoso, destinava-se o rigor de uma internação em estabelecimentos "adequados" até que cessasse sua condição de periculosidade, utilizando-se das mesmas expressões contidas no Código Penal para designar a periculosidade presumida.

Na hipótese da condição de periculosidade não cessar até os 21 anos, abria-se a possibilidade de uma internação ad infinitum, através da transferência do menor a uma colônia agrícola ou estabelecimento congênere, segundo o Decreto-lei 3.914/41. Veja-se, assim, que o mesmo dispositivo usado até os dias atuais para o prolongamento da internação de inimputáveis na condição de loucos de todo o gênero já era previsto para a segregação do menor perigoso nesse período.

A incorporação, ilegal, da construção jurídica periculosidade, prevista originalmente no Código Penal, para o tratamento da infância abandonada, abriu assim um precedente para um novo padrão de categorização e institucionalização do menor. Primeiramente, por ter deixado ainda mais claro a quem se destinava o controle policial e a institucionalização: ao menor abandonado, pobre, em geral negro $^{10}$, sem vínculos familiares ou institucionais reconhecidos. Em segundo lugar, tornou nítida a percepção da periculosidade como condição imanente à menoridade abandonada, o que viabilizou um nível ainda maior de sujeição do menor, produzindo, no que toca a um projeto disciplinador, consequências diversas (TEIXEIRA, 2012).

$\mathrm{Na}$ base dos novos instrumentos legais e do renovado tratamento jurídico dispensado ao menor, estava uma política nacional que pretendia estabelecer em torno da menoridade um programa institucionalizador ${ }^{11}$ de maior monta e permanência. Era visando acrescer novos controles ao percurso dos menores detidos nas ruas até os anos 1940, caracterizado sinteticamente pelo ciclo "apreensão-Juizado-liberdade”, que essa política e seus aportes institucionais estavam dirigidos.

Para tanto, era necessário, primeiro, isolar a menoridade infratora, presumidamente perigosa, da menoridade abandonada, apenas potencialmente perigosa, acabando com uma espécie de indistinção que os controles policiais e a institucionalização incompleta estabeleciam entre elas. Como se depreende dos relatos dos

10 Os dados de detenções correcionais entre os anos 1937-1943, estratificados por cor, apontam a uma sobrerrepresentação de negros e pardos entre os menores detidos, ainda maior quando se tratava de menores do sexo feminino.

$11 \mathrm{O}$ Rio de Janeiro, capital federal à época, sairia à frente neste projeto, tendo criado logo em 1941 o SAM - Serviço de Assistência ao Menor -, para dar assistência aos menores desvalidos e delinquentes (Decreto-lei 3.799/1941). O órgão, subordinado ao Ministério da Justiça, já indicava em sua criação tratar-se antes de um aparato voltado mais à segurança pública do que à assistência social, antecipando o tratamento da questão do menor nas raias de um problema de polícia. 
chefes de polícia nos anos 1930, as apreensões de menores, abandonados, viciosos ou infratores, e seu eventual encaminhamento a instituições de internação eram realizados sem qualquer especificidade em relação ao infrator, seu prognóstico e tratamento "diferenciado".

Era necessário, então, tomar o crime, ou melhor, a menoridade infratora perigosa como categoria jurídica e política, para que, em torno dela, se delineasse uma vigilância especializada e uma gama de novos saberes, tendo como referência um percurso institucional mais definido.

Não obstante tais transformações terem ganhado o plano da cidade apenas no começo da década de 1950, o menor abandonado infrator, enquanto categoria socialmente perigosa, ingressava, já nos anos 1940, nos desígnios de uma política prisional que pretendia seu isolamento e disciplinarização. Pelo Decreto-lei 12.924 de 04/09/1942, criava-se o Instituto Correcional da Ilha Anchieta, ${ }^{12}$ com a finalidade de operar como modelo de excelência disciplinar no sistema penitenciário. Regulamentado em 12 de janeiro de 1943 pelo Decreto 13.182, apresentava, entre suas funções precípuas, internar os adultos sujeitos à medida de segurança detentiva, ou seja, os socialmente perigosos, e aqueles que eram enviados pela Penitenciária do Estado para cumprir sanções disciplinares. Além desse público-alvo, também se instituía, nesse mesmo complexo prisional, o Educandário Anchieta, cuja função era internar os menores que tenham completado 16 anos de idade e se mostrem perigosos pelo seu estado de perversão moral, ou seja, os socialmente perigosos menores. ${ }^{13}$

A partir de 1955, a Casa de Custódia e Tratamento de Taubaté, que passará a assumir, entre outras finalidades, as do extinto Presídio da Ilha Anchieta, terá entre suas destinações a previsão de receber menores entre 16 e 21 anos presumidamente perigosos, juntamente com os adultos na mesma condição, além de inimputáveis, situação essa que se prolongará até os anos 1980 (GoMES ET AL,1986, p.41).

Já no contexto da cidade de São Paulo, os anos 1950 irão assinalar o momento em que a política esboçada com a normativa dos anos 1940 irá ganhar um plano de maior concretude. Será o Judiciário o primeiro a dar um passo nesse sentido, ao criar, em 1953, o Serviço de Abrigo e Triagem (SAT), subordinado ao Juizado de

12 Esse estabelecimento foi fundado originalmente em 1908 como Colônia Correcional da Ilha dos Porcos, tendo se transformado em presídio político no início da Era Vargas e, depois, em colônia correcional agrícola.

13 Note-se que o mesmo decreto que instituiu a aplicação aos menores da categoria periculosidade previu a possibilidade de, "em casos excepcionais", o menor vir a ser internado em estabelecimentos de custódia para adultos, até que cessasse sua periculosidade (BrasiL, Decreto-lei 6.026, 1943 , art. $2^{\circ}$, parágrafo $1^{\circ}$ ). 
Menores, que se destinava a, além de um primeiro recolhimento institucional, as atividades de classificação de menores, marcando um dos momentos de ingresso de saberes especializados, como a psicologia, no interior da justiça em São Paulo.

Luiz Alberto Mendes (2001) narra sua passagem pelo SAT, quando, aos doze anos de idade, fora recolhido por perambular as ruas da cidade ao estilo de um "um menor abandonado", no início da década de 1960. Seu depoimento dá conta dos arranjos que se estabeleciam em suposta resposta a uma aparente precariedade organizacional, mas que, na verdade, operavam de modo a difundir a violência entre os próprios menores, a partir da lógica de funcionamento do local:

Conduziram-me para um enorme alojamento, cheio de beliches. Era o plantão do SAT, local onde eram recolhidos os menores de rua com menos de quatorze anos que viviam de pequenos roubos na cidade. [...] Os maiores que tomavam conta de nós batiam à menor falha. Havia garotos débeis mentais, e esses apanhavam mais pois não entendiam as ordens. [...] Havia os maiores que eram chamados de bocas de fogo. Explicavam, eles “comiam” os meninos mais bobos, principalmente os débeis [...] Esses garotos maiores eram do Instituto Modelo, um prédio próximo. Crianças sem pai que o governo criava desde o berçário. Trabalhavam ali, tomando conta de nós, para pagar o pão que comiam (MENDES, 2001, p.15).

No ano seguinte, em 1954, o Poder Executivo, em consonância ao SAM carioca, criava o Recolhimento Provisório de Menores (RPM), destinado fundamentalmente aos menores infratores entre 14 e 18 anos do sexo masculino, e o Centro de Observação Feminina (COF), destinado às infratoras do sexo feminino. ${ }^{14}$ A criação do RPM e do COF marca o momento, no plano da cidade, em que a menoridade criminosa ingressa definitivamente nos desígnios de uma política de segurança pública, e em que a suposta questão social que nela ainda se embutia se dilui.

Marca também o momento de consolidação de um modo de tratar o menor abandonado infrator que se balizará pela mesma lógica que pautara, desde há muito, o sistema repressivo no país, sobretudo no que se refere à exacerbada violência institucional e à corrupção endêmica. Em diferença aos abrigos e reformatórios que recebiam, até os anos 40, o grande contingente de menores abandonados,

14 O RPM e o COF nascem vinculados à Secretaria Estadual de Bem-Estar Social, e sujeitos à fiscalização do Juizado de Menores, diante da centralidade que esse órgão desempenhava na estrutura normativa prevista pelo Código de Menores. Eles permanecerão vinculados à referida Secretaria até 1975; em 1973, é criada a Fundação Paulista de Promoção Social Menor (PRÓ-MENOR), segundo as diretrizes da PNBEM, e, no ano seguinte, a FEBEM - Fundação Estadual de Bem-Estar do Menor (PassetTi, 1999). 
eventualmente infratores, no modelo de aprisionamento que o RPM consolida, a única finalidade que sobressai é a contenção, o isolamento, marcados pela mesma lógica dos estabelecimentos prisionais. Esse modelo encerrará assim o circuito ruas/crime/reincidência, empurrando o menor abandonado gradativamente para as raias da delinquência.

\section{REFERÊNCIAS BIBLIOGRÁFICAS}

Adorno, Sérgio. "A experiência precoce da punição", In: martins, José de Souza (org.). A criança sem infância no Brasil. São Paulo: Hucitec, 1993.

Alvarez, Marcos César. A emergência do Código de Menores de 1927: uma análise do discurso jurídico e institucional da assistência e proteção aos menores. Dissertação (mestrado). Faculdade de Filosofia, Letras e Ciências Humanas da Universidade de São Paulo, 1989.

Bacharéis, Criminologistas e Juristas: Saber Jurídico e a Nova Escola Penal no Brasil. São Paulo: IBCCRIM, 2003.

Bruno, Aníbal. Teoria da Perigosidade Criminal. Revista dos Tribunais, São Paulo, vol.779, ano 89, p. 753-776, set. 2000.

CARRARA, Sérgio. Crime e loucura: o aparecimento do manicômio judiciário na passagem do século. Rio de Janeiro: EdUERJ/EdUSP, 1998.

CEBrap - CENTRO BRASILEIRO DE ANÁliSE E PLANEJAMENTO. A CRIANÇA, o adolescente, a cidade. São Paulo, 1972, mimeo.

CoRrÊA, Mariza. "Antropologia e medicina legal: variações em torno de um mito”. In: voGT, Carlos et al (org.). Caminhos cruzados: linguagem, antropologia e ciências naturais, São Paulo: Brasiliense, 1982, p.53-63.

FAusto, Boris. Crime Cotidiano: a criminalidade em São Paulo (1880-1924). São Paulo: Companhia das Letras, 2000.

Foucault, Michel. História da Loucura na Idade Clássica. Tradução de José Teixeira Coelho Netto. São Paulo: Perspectiva, 2003.

. Naissance de la Biopolitique. Cours au Collège de France (1978- 1979), Paris: Gallimard, 2004.

. “A evolução da noção de 'indivíduo perigoso' na psiquiatria legal do século XIX”. In: Foucault, Michel. Ética, sexualidade, política. Col. Ditos e Escritos, Vol. 5, Rio de Janeiro: Forense Universitária, 2006.

Fry, Peter; Carrara, Sergio. As vicissitudes do liberalismo no direito penal brasileiro. Revista Brasileira de Ciências Sociais, São Paulo, v. 2, n. 11, p. 48-54, 1986. 
Gomes et al., Casa de Custódia de Taubaté (it). In: Pinheiro, Paulo Sérgio e braun, Eric (Orgs.). Democracia $x$ Violência. Reflexões para a Constituinte, Rio de Janeiro: Paz e Terra, 1986, pp. 41-4.

Matsuda, Fernanda Emy. A medida da maldade. Periculosidade e Controle Social no Brasil. Dissertação (mestrado). Faculdade de Filosofia, Letras e Ciências Humanas da Universidade de São Paulo, 2009.

Mendes, Luiz Alberto. Memórias de um Sobrevivente. São Paulo: Companhia das Letras, 2001.

Miranda, Carlos Alberto Cunha. "A fatalidade biológica: a medição dos corpos, de Lombroso aos biotipologistas". In: MAIA, Clarisse Nunes et al (org.). História das Prisões no Brasil - Vol. II. Rio de Janeiro: Rocco, 2009, p. 277-317.

Passetti, Edson. “Crianças carentes e políticas públicas”. In: DEL PRIORE, M. (org.). História das crianças no Brasil, São Paulo: Contexto, 1999, p. 347-375.

QueIrolo, Silvia C. O espaço conceitual da periculosidade: direito penal e criminologia. Dissertação (mestrado). Faculdade de Direito da Universidade de São Paulo, 1984.

Teixeira, Alessandra. Construir a delinquência, articular a criminalidade. Um estudo sobre a gestão dos ilegalismos na cidade de São Paulo. Tese (doutorado). Faculdade de Filosofia, Letras e Ciências Humanas da Universidade de São Paulo, 2012.

\section{FONTES PRIMÁRIAS}

A ESTATÍSTICA POLICIAL-CRIMINAL DO ESTADO DE SÃO PAULO, volume I. Ano de 1938. São Paulo: Tipografia do Gabinete de Investigações, 1939.

A ESTATÍSTICA POLICIAL-CRIMINAL DO ESTADO DE SÃO PAULO, volume II. Ano de 1939. São Paulo: Tipografia do Gabinete de Investigações, 1940.

A ESTATÍSTICA POLICIAL-CRIMINAL DO ESTADO DE SÃO PAULO, volume III. Ano de 1940. São Paulo: Tipografia do Gabinete de Investigações, 1941.

A ESTATÍSTICA POLICIAL-CRIMINAL DO ESTADO DE SÃO PAULO, volume IV. Ano de 1941. São Paulo: Tipografia do Gabinete de Investigações, 1942.

A ESTATÍSTICA POLICIAL-CRIMINAL DO ESTADO DE SÃO PAULO, volume V. Ano de 1942. São Paulo: Tipografia do Gabinete de Investigações, 1943.

A ESTATÍSTICA POLICIAL-CRIMINAL DO ESTADO DE SÃO PAULO, volume VI. Ano de 1943. São Paulo: Tipografia do Gabinete de Investigações, 1944.

BRASIL. CÓDIGO PENAL. DECRETO-LEI 2.848, de 7 de dezembro de 1940. Disponível em: <http://www.planalto.gov.br/ccivil_03/Decreto-lei/Del2848compilado.htm>. Acesso em: 14 de julho de 2017. 
. Lei das contravenções penais. Decreto-lei n ${ }^{0}$ 3.688, de 3 de outubro de 1941. Disponível em: <http://www.planalto.gov.br/ccivil_03/Decreto-lei/Del3688.htm>. Acesso em: 14 de julho de 2017.

Lei de introdução do Código Penal e da Lei das Contravenções Penais. Decreto-lei no 3.914 , de 9 de dezembro de 1941. Disponível em: <http://www.planalto. gov.br/ccivil_03/decreto-lei/del3914.htm>. Acesso em: 14 de julho de 2017.

. Decreto-lei 3.799, de 5 de novembro de 1941. Disponível em: http://www2. camara.leg.br/legin/fed/declei/1940-1949/decreto-lei-3799-5-novembro-1941413971-publicacaooriginal-1-pe.html. Acesso em: 14 de julho de 2017.

. Decreto-lei 6.026, de 24 de novembro de 1943. Dispõe sobre as medidas aplicáveis aos menores de 18 anos pela prática de fatos considerados infrações penais e dá outras providências. Disponível em: <http://www2.camara.leg.br/legin/fed/ declei/1940-1949/decreto-lei-6026-24-novembro-1943-416164-publicacaooriginal1-pe.html>. Acesso em: 14 de julho de 2017.

RELATÓRIO DO GABINETE DE INVESTIGAÇÕES RELATIVO AO ANO DE 1936. Secretaria de Negócios da Segurança Pública. São Paulo: Tipografia do Gabinete de Investigações, 1937.

RELATÓRIO DAS ATIVIDADES DA POLÍCIA CIVIL NO EXERCÍCIO DE 1939, apresentado pelo Chefe de Polícia ao interventor do Estado. Secretaria de Segurança Pública. São Paulo: SSP, 1939.

RELATÓRIO DAS ATIVIDADES DA POLÍCIA CIVIL NO EXERCÍCIO DE 1939, apresentado pelo Chefe de Polícia ao interventor do Estado. Secretaria de Segurança Pública. São Paulo: SSP, 1939. 